\title{
Understanding the Role of $\mathrm{NH}_{4} \mathrm{~F}$ and $\mathrm{Al}_{2} \mathrm{O}_{3}$ Surface Co-modification on Lithium-Excess Layered Oxide $\mathrm{Li}_{1.2} \mathrm{Ni}_{0.2} \mathrm{Mn}_{0.6} \mathrm{O}_{2}$
}

Haodong Liu, ${ }^{\dagger}$ Danna Qian, ${ }^{\dagger}$ Michael G. Verde, ${ }^{\dagger}$ Minghao Zhang, ${ }^{\dagger}$ Loïc Baggetto, ${ }^{\ddagger}$ Ke An, ${ }^{\S}$ Yan Chen, ${ }^{\S}$ Kyler J. Carroll, ${ }^{\dagger}$ Derek Lau, ${ }^{\dagger}$ Miaofang Chi, ${ }^{\prime \prime}$ Gabriel M. Veith, ${ }^{\dagger}$ and Ying Shirley Meng* ${ }^{*}$,

${ }^{\dagger}$ Department of NanoEngineering, University of California San Diego, La Jolla, California 92121-2460, United States

${ }^{\ddagger}$ Materials Science and Technology Division, ${ }^{\S}$ Chemical and Engineering Materials Division, and ${ }^{\|}$Center for Nanophase Materials Sciences, Oak Ridge National Laboratory, Oak Ridge, Tennessee 37831, United States

\section{Supporting Information}

ABSTRACT: In this work we prepared $\mathrm{Li}_{1.2} \mathrm{Ni}_{0.2} \mathrm{Mn}_{0.6} \mathrm{O}_{2}$ (LNMO) using a hydroxide co-precipitation method and investigated the effect of co-modification with $\mathrm{NH}_{4} \mathrm{~F}$ and $\mathrm{Al}_{2} \mathrm{O}_{3}$. After surface co-modification, the first cycle Coulombic efficiency of $\mathrm{Li}_{1.2} \mathrm{Ni}_{0.2} \mathrm{Mn}_{0.6} \mathrm{O}_{2}$ improved from $82.7 \%$ to $87.5 \%$, and the reversible discharge capacity improved from 253 to $287 \mathrm{mAh} \mathrm{g}^{-1}$ at $\mathrm{C} / 20$. Moreover, the rate capability also increased significantly. A combination of neutron diffraction (ND), high-resolution transmission electron microscopy (HRTEM), aberration-corrected scanning transmission electron microscopy (a-STEM)/electron energy loss spectroscopy (EELS), and X-ray photoelectron spectroscopy (XPS) revealed the changes of surface structure and chemistry after $\mathrm{NH}_{4} \mathrm{~F}$ and $\mathrm{Al}_{2} \mathrm{O}_{3}$ surface co-modification while the bulk properties showed relatively no changes. These complex changes on the material's surface include the formation of an amorphous $\mathrm{Al}_{2} \mathrm{O}_{3}$ coating, the transformation of layered material to a spinel-like phase on the surface, the formation of nanoislands of active material, and the partial chemical reduction of surface $\mathrm{Mn}^{4+}$. Such enhanced discharge capacity of the modified material can be primarily assigned to three aspects: decreased irreversible oxygen loss, the activation of cathode material facilitated with preactivated $\mathrm{Mn}^{3+}$ on the surface, and stabilization of the Ni-redox pair. These insights will provide guidance for the surface modification in high-voltage-cathode battery materials of the future.

KEYWORDS: Li excess, Li-ion battery, surface modification, spinel-like phase, Li rich, cathode, high energy density

\section{INTRODUCTION}

To meet the requirements for electric vehicles (EVs), better cathode materials with higher energy density and longer cycle life have to be developed. The Li-excess layered oxide compounds, $x \mathrm{Li}_{2} \mathrm{MnO}_{3} \cdot(1-x) \mathrm{LiMO}_{2}(\mathrm{M}=\mathrm{Ni}, \mathrm{Mn}$, and $\mathrm{Co}$ ), are one potential class of cathode materials due to their high energy density and relatively lower costs. ${ }^{1}$ Despite the fact that Li-excess materials may exhibit reversible discharge capacities greater than $280 \mathrm{mAh} \mathrm{g}^{-1}$ (almost twice the practical capacity of $\left.\mathrm{LiCoO}_{2}\right),{ }^{2-4}$ there are several inherent material issues that limit its practical application. The first one is the large irreversible capacity observed in the first cycle, which lowers the initial Coulombic efficiency. Second, the rate capability does not satisfy high-power applications. However, the most serious concern is the severe capacity and voltage degradation after long cycles, which results in a significant decrease in energy density. ${ }^{5}$

In order to remediate these issues several surface modification methods have been applied to the cathode particles to decrease potential side reactions between electrode and electrolyte, such as HF etching and the formation of undesirable products within the solid-electrolyte interface (SEI) film. ${ }^{6}$ The most widely used surface modification materials are oxides, fluorides, and phosphates, for example, $\mathrm{TiO}_{2}, \mathrm{Al}_{2} \mathrm{O}_{3}, \mathrm{AlF}_{3}$, and $\mathrm{AlPO}_{4}{ }^{7-9}$ However, most of these materials are intrinsically electronic semiconductors or insulators. Learning from the case of $\mathrm{LiFePO}_{4}$, carbon and aluminum have been used as a coating layer in order to improve the electronic conductivity of the material. ${ }^{10,11}$ Other researchers have introduced an ionic conductor to the surface of $\mathrm{Li}$ excess, such as, lithium phosphorus oxynitride (LiPON), $\mathrm{LiNiPO}_{4}$, and $\mathrm{Li}_{3} \mathrm{VO}_{4}{ }^{12-15}$ Manthiram et al. combined the advantages of different surface modifications and developed hybrid strategies. One of their recent works combined reduced graphene oxide and $\mathrm{AlPO}_{4}$, which largely suppressed undesired SEI formation. ${ }^{16}$ In contrast to the studies mentioned earlier, Kang and Thackeray demonstrated that a mild acid treatment

Received: June 4, 2015

Accepted: August 19, 2015

Published: August 19, 2015 
can also reduce the first cycle irreversible capacity of Li-excess layered oxides. ${ }^{17}$

Although these surface modifications improved the electrochemical performance of $\mathrm{Li}$ excess, the fundamental role in terms of their chemical and structural effects is still not well understood. In this work, we prepared $\mathrm{Li}$-excess layered oxide with composition of $\mathrm{Li}_{1.2} \mathrm{Ni}_{0.2} \mathrm{Mn}_{0.6} \mathrm{O}_{2}$ (LNMO) using a routine hydroxide co-precipitation method. A mild acid, $\mathrm{NH}_{4} \mathrm{~F}$, and metal precipitant, $\mathrm{Al}^{3+}$, were used together to modify the surface of $\mathrm{Li}$ excess. Our analysis focuses on a mechanistic study aimed to determine the reasons for the electrochemical enhancement. First, the bulk crystal structures and morphologies of these materials were examined. Then, a series of surface sensitive characterizations were carried out to investigate the chemical and structural changes after surface co-modification. The combination of electrochemical analyses and physical characterization enabled us to explain how the $\mathrm{NH}_{4} \mathrm{~F}$ and $\mathrm{Al}_{2} \mathrm{O}_{3}$ surface co-modification improved the initial Coulombic efficiency, rate capability, and changed cycling stability of $\mathrm{Li}$ excess. These findings help us understand the working mechanisms of surface modifications which will shed light on designing reasonable surface modifications for high-voltagecathode materials in the future.

\section{EXPERIMENTAL METHODS}

2.1. Synthesis and Surface Modification. A co-precipitation reaction, followed by two-step calcination was used for the synthesis of the Li-excess layered oxides. ${ }^{18,19}$ Transition metal (TM) nitrates, $\mathrm{Ni}\left(\mathrm{NO}_{3}\right)_{2} \cdot 6 \mathrm{H}_{2} \mathrm{O}$ (ACROS Organics, 99\%), and $\mathrm{Mn}\left(\mathrm{NO}_{3}\right)_{2} \cdot 4 \mathrm{H}_{2} \mathrm{O}$ (Alfa Aesar, 98\%), were dissolved into deionized water and then titrated into $\mathrm{LiOH} \cdot \mathrm{H}_{2} \mathrm{O}$ (Fisher) solution. The precipitated TM hydroxides were then subjected to vacuum filtration and washed three times with deionized water. The collected TM hydroxides were dried in an oven at $180{ }^{\circ} \mathrm{C}$ for $10 \mathrm{~h}$ in air. The dried TM precursors were then mixed with a stoichiometric amount of $\mathrm{LiOH} \cdot \mathrm{H}_{2} \mathrm{O}$ (Fisher). This mixture was ground for $30 \mathrm{~min}$ to ensure adequate mixing and then placed into a furnace at $480{ }^{\circ} \mathrm{C}$ for $12 \mathrm{~h}$. Later, the precalcined powders were calcinated at $900{ }^{\circ} \mathrm{C}$ for $12 \mathrm{~h}$ in air, to achieve the final product.

The procedure for preparing $\mathrm{NH}_{4} \mathrm{~F}$ and $\mathrm{Al}_{2} \mathrm{O}_{3}$ surface co-modified Li excess (NALNMO) was adapted from work by Zheng et al. ${ }^{7}$ The specific amounts of $\mathrm{NH}_{4} \mathrm{~F}$ and $\mathrm{Al}^{3+}$ in this work were 3 and $1 \mathrm{~mol} \%$ of the $\mathrm{Li}_{1.2} \mathrm{Ni}_{0.2} \mathrm{Mn}_{0.6} \mathrm{O}_{2}$ powders, respectively. To prepare $\mathrm{NH}_{4} \mathrm{~F}$ and $\mathrm{Al}_{2} \mathrm{O}_{3}$ surface co-modified $\mathrm{Li}_{1.2} \mathrm{Ni}_{0.2} \mathrm{Mn}_{0.6} \mathrm{O}_{2}$ powders, $\mathrm{NH}_{4} \mathrm{~F}$ (Aldrich, 99.99\%) and $\mathrm{Al}\left(\mathrm{NO}_{3}\right)_{3} \cdot 9 \mathrm{H}_{2} \mathrm{O}$ (Aldrich, 99.997\%) were separately dissolved in deionized water. First, the $\mathrm{Li}_{1.2} \mathrm{Ni}_{0.2} \mathrm{Mn}_{0.6} \mathrm{O}_{2}$ powders were dispersed into the aluminum nitrate solution by continuous magnetic stirring at the controlled temperature of $80{ }^{\circ} \mathrm{C}$. Then, the $\mathrm{NH}_{4}^{+}$ solution was slowly dropped into the solution, followed by a slow evaporation of solvent. The obtained precursor was heated at $400{ }^{\circ} \mathrm{C}$ in a tube furnace for $5 \mathrm{~h}$ under the flow of nitrogen gas.

2.2. Neutron Diffraction. The time-of-fight (TOF) powder neutron diffraction data were collected at the VULCAN instrument at Spallation Neutron Sources (SNS), Oak Ridge National Laboratory (ORNL). ${ }^{20}$ Around $0.6 \mathrm{~g}$ of powder was filled into a vanadium sample can. An incident beam $(5 \mathrm{~mm} \times 12 \mathrm{~mm})$ of $0.7-3.5 \AA$ bandwidth, allowing $0.5-2.5 \AA$ d-space in the diffracted pattern of the $\pm 90^{\circ} 2 \theta$ detector banks, was selected using the double-disk choppers at $30 \mathrm{~Hz}$ frequency. High-resolution mode was employed with $\Delta d / d \sim 0.25 \%$. The SNS was at nominal, $1100 \mathrm{KW}$, power. ${ }^{20}$ Powder neutron diffraction data were collected in high-resolution mode for a duration of $3 \mathrm{~h}$ and processed using VDRIVE software. ${ }^{21}$ Full pattern Rietveld refinement was performed to extract the structure parameters using GSAS software with EXPGUI interface. ${ }^{22,23}$

2.3. Scanning Electron Microscopy. The particle morphology and size distribution of the synthesized powders were determined using an FEI XL30 ultrahigh-resolution scanning electron microscope
(UHR SEM) system with a Sirion column, which enables very high resolution imaging at low acceleration voltage. All images were collected under an accelerating voltage of $15 \mathrm{kV}$. The powders were suspended on double-sided carbon tape, placed on a specimen holder.

2.4. High-Resolution Transmission Electron Microscopy. HRTEM images were collected using an FEI Tecnai G2 Polara cryoelectron microscope with a field emission gun and a voltage of 300 $\mathrm{kV}$. The powders were suspended on a 300-mesh copper grid with lacey carbon.

2.5. Electrochemical Test. Electrochemical properties were measured using an Arbin battery cycler in galvanostatic mode between 4.8 and $2.0 \mathrm{~V}$. Cathodes were prepared by mixing the active material, LNMO or NALNMO, with 10 wt \% Super P carbon (TIMCAL) and $10 \mathrm{wt} \%$ poly(vinylidene fluoride) (PVDF) in $N$-methylpyrrolidone (NMP, 99\% extra pure, ACROS Organics). The slurry was cast onto an $\mathrm{Al}$ foil using a doctor blade and dried in a vacuum oven overnight at $80^{\circ} \mathrm{C}$. The electrode discs were punched and dried again at $80^{\circ} \mathrm{C}$ for $6 \mathrm{~h}$ before storing them in an argon-filled glovebox $\left(\mathrm{O}_{2}, \mathrm{H}_{2} \mathrm{O}\right.$ level $<1$ ppm). 2016-type coin cells were used to electrochemically cycle LNMO and NALNMO to different cycles. The coin cells were prepared in the same argon-filled glovebox using lithium metal ribbon as anode and $1 \mathrm{M} \mathrm{LiPF}_{6}$ in ethylene carbonate/dimethyl carbonate (EC:DMC in 1:1 volume ratio) electrolyte solution (Novolyte). Celgard polymer film (C480, Celgard Inc., Charlotte, NC, USA) were used as the separator. The loading of active material was around 3.7 $\mathrm{mg} \mathrm{cm} \mathrm{cm}^{-1}$ for both LNMO and NLNMO. Multiple cells were electrochemically tested to confirm reproducibility.

The cycled samples were recovered by disassembling cycled batteries in an argon-filled glovebox. The cathode was washed with DMC three times and then allowed to dry in argon atmosphere overnight. The cathodes were transferred to the XPS chamber using an airtight vacuum transfer system. For TEM samples, the powders were suspended on a copper grid with lacey carbon. The approximate time of sample exposed to air (from a sealed environment to the microscope column) was less than $5 \mathrm{~s}$.

2.6. X-ray Photoelectron Spectroscopy. Surface chemistry was probed using a $\mathrm{PHI} 3056 \mathrm{X}$-ray photoelectron spectrometer equipped with a dual $\mathrm{Al} \mathrm{K} \alpha(1486.7 \mathrm{eV})$ and $\mathrm{Mg} \mathrm{K} \alpha(1256.6 \mathrm{eV})$ anode source, operated at $350 \mathrm{~W}$, and with sample chamber pressure below $10^{-8}$ Torr. Samples were dissembled in an argon-filled glovebox, rinsed with a small quantity of anhydrous DMC (Sigma-Aldrich), and transferred to the XPS chamber using an airtight vacuum transfer system. Highresolution scans were acquired using a pass energy of $23.5 \mathrm{eV}$ and an energy step of 0.05 or $0.075 \mathrm{eV}$. Survey scans were measured using a pass energy of $93.5 \mathrm{eV}$ and a $0.5 \mathrm{eV}$ energy step. The binding energies were calibrated by setting the hydrocarbon $\mathrm{C}$ is $(\mathrm{C}-\mathrm{C}, \mathrm{C}-\mathrm{H})$ signal to $284.6 \mathrm{eV}$, which corresponds mainly to the carbon black in the composite electrode and adventitious carbon. $\mathrm{C}$ signal was measured before and after any other signal to precisely calibrate the energy scale. The data were analyzed using CasaXPS software, and all peaks were fit using a Shirley-type background.

2.7. a-STEM/EELS. Electron microscopy work was carried out on a Cs-corrected FEI Titan 80/300 kV TEM/STEM microscope, equipped with a Gatan Image Filter Quantum-865. All STEM images and EELS spectra were acquired at $300 \mathrm{kV}$ and with a beam size of $\sim 0.7 \AA$ Å. EELS spectra shown in this work were acquired from a square area of $\sim 0.5 \times 0.5 \mathrm{~nm}^{2}$ using an acquisition time of $2 \mathrm{~s}$ and a collection angle of $35 \mathrm{mrad}$. High-angle annular dark field (HAADF) images were obtained at a convergence angle of $30 \mathrm{mrad}$ and a large inner collection angle of 65 mrad. Images acquired by an HAADF detector with a small convergence angle and a relatively large inner collection angle are also called "Z-contrast" images, where the contrast is proportional to $\mathrm{Z}^{1.7} \cdot{ }^{24,25}$

To minimize possible electron beam irradiation effects, EELS and HAADF figures presented in this work were acquired from areas without prebeam irradiation. $\mathrm{Mn}_{3}$ to $\mathrm{L}_{2}$ intensity ratio analysis was performed using the method described by Wang et al. ${ }^{26}$ 


\section{RESULTS}

3.1. Bulk Crystal Structure and Morphology Characterization. Figure 1 represents the SEM images of the LNMO
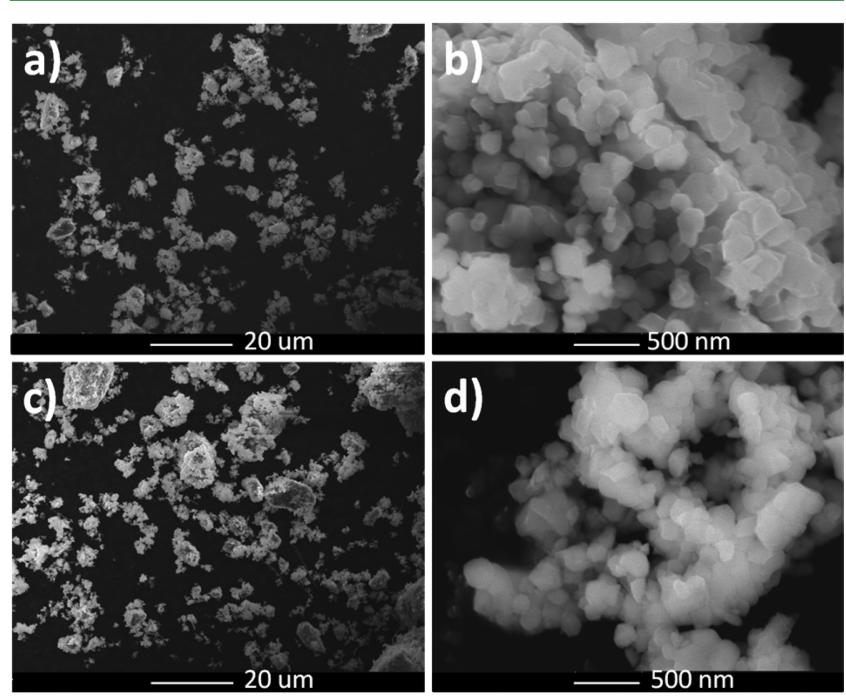

Figure 1. SEM images: (a and b) LNMO; (c and d) NALNMO.

and NALNMO. Both materials show secondary particles with a wide size distribution, ranging from 1 to $10 \mu \mathrm{m}$; the primary particle size distribution ranges from 80 to $150 \mathrm{~nm}$. The SEM images show no morphology or particle size difference between LNMO and NALNMO. The presence of $\mathrm{Al}$ was confirmed using EDS, which is shown in Supporting Information (SI) Figure S1.

Due to the low scattering cross-section of lithium in X-ray scattering, neutron diffraction was carried out on both LNMO and NALNMO powders in order to carefully investigate their crystal structures. ${ }^{27}$ Figure 2 shows the neutron diffraction and Rietveld refinement of both samples. The major diffraction peaks of these two materials are indexed according to the parent hexagonal structure with $R \overline{3} m$ space group. The patterns indicate that both samples adopt a well-layered structure with little $\mathrm{Li} / \mathrm{Ni}$ mixing, as evidenced by the existence of doublets at $(006) /(012)$ and $(018) /(110){ }^{28,29}$ No obvious changes were observed in these peaks after $\mathrm{NH}_{4} \mathrm{~F}$ and $\mathrm{Al}_{2} \mathrm{O}_{3}$ surface comodification, indicating that the layered phase is wellmaintained. In addition, there are no extra peaks observed in NALNMO.

Table 1 lists the summary of Rietveld refinement results. The lattice parameters of LNMO are $a=2.8615(1) \AA$ and $c=$ 14.2580 (6) $\AA$, which are in good agreement with our previous XRD studies. ${ }^{30}$ The refined oxygen position of the pristine material is $(0,0,0.2417(7))$, and there is $3.7(4) \% \mathrm{Ni}$ in the $\mathrm{Li}$ layer. As a comparison, the lattice parameters of NALNMO surface co-modified material are $a=2.8623(1) \AA$ and $c=$ $14.2621(6) \AA$, which are only slightly larger $(<0.03 \%)$ than those of the LNMO. The oxygen position after $\mathrm{NH}_{4} \mathrm{~F}$ and $\mathrm{Al}_{2} \mathrm{O}_{3}$ surface co-modification is unchanged at $(0,0$, $0.2416(7)$ ), and there is slightly more $\mathrm{Ni}^{2+}$ in the Li layer, which is $3.9(4) \%$. In summary, the neutron diffraction study shows that the surface co-modification by $\mathrm{NH}_{4} \mathrm{~F}$ and $\mathrm{Al}_{2} \mathrm{O}_{3}$ does not change the bulk structure of $\mathrm{Li}_{1.2} \mathrm{Ni}_{0.2} \mathrm{Mn}_{0.6} \mathrm{O}_{2}$; the layered $\mathrm{O} 3$ structure is well-maintained after the surface modification. The process introduces only slight changes in the material's lattice parameters and $\mathrm{Li} / \mathrm{Ni}$ interlayer mixing.
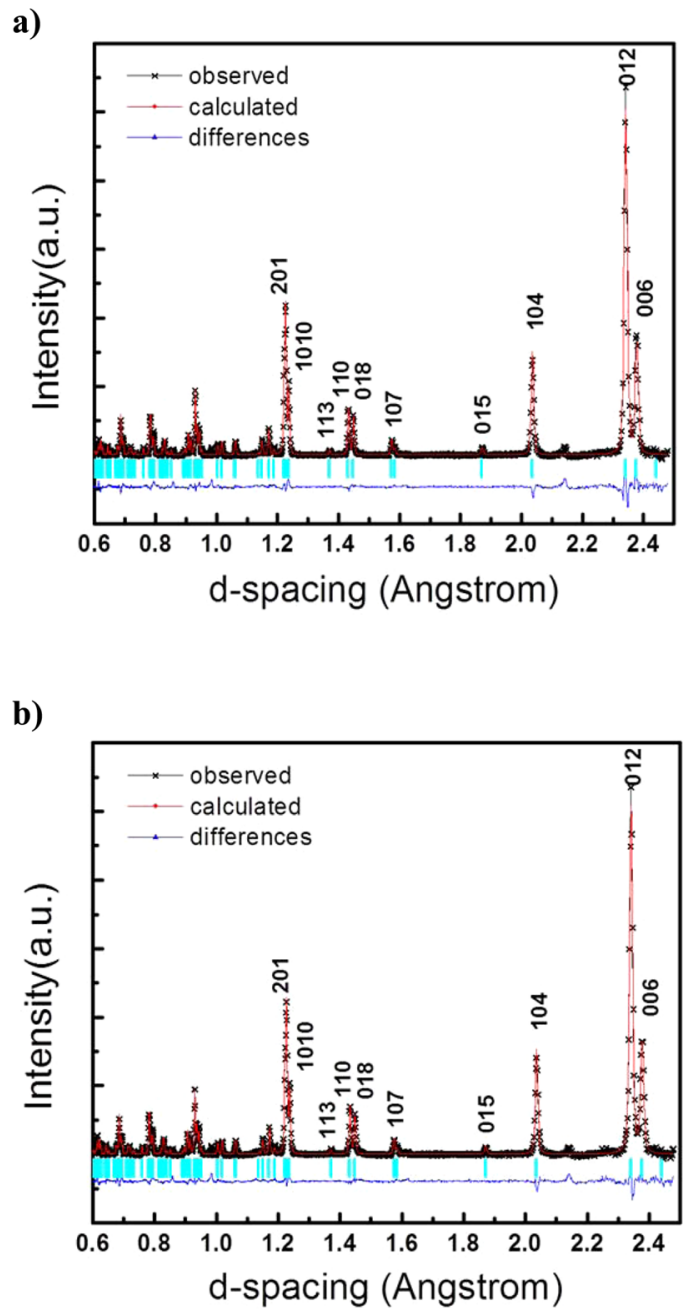

Figure 2. ND patterns of (a) LNMO and (b) NALNMO. The black crosses represent the observed pattern, the red line corresponds to the calculated diffraction pattern, and the blue line shows the differences between observed and calculated patterns.

3.2. Electrochemical Performance. Figure 3a compares the first charge/discharge voltage profiles of LNMO and NALNMO within the voltage window of $2-4.8 \mathrm{~V}$, at $12.5 \mathrm{~mA}$ $\mathrm{g}^{-1}(\mathrm{C} / 20)$. The surface modified sample shows the same characteristic profile, with a sloping region (to $4.4 \mathrm{~V}$ ) corresponding to the oxidation of nickel from $\mathrm{Ni}^{2+}$ to $\mathrm{Ni}^{4+}$, followed by the oxidation of oxygen from the lattice during the voltage plateau region. ${ }^{3,30-32}$ Even without deducting the weight of nonactive $\mathrm{Al}_{2} \mathrm{O}_{3}$ in NALNMO, the surface modified material still shows higher charge and discharge specific capacity than the pristine material. After $\mathrm{NH}_{4} \mathrm{~F}$ and $\mathrm{Al}_{2} \mathrm{O}_{3}$ surface co-modification, charge and discharge capacities are increased from $306 \pm 6$ to $328 \pm 4 \mathrm{mAh} \mathrm{g}^{-1}$ and from $253 \pm 2$ to $287 \pm 6 \mathrm{mAh} \mathrm{g}^{-1}$, respectively, as well as Coulombic efficiency from $82.7 \%$ to $87.5 \%$. More importantly, the irreversible capacity was reduced from $53 \pm 8(\sim 17 \%)$ to 41 $\pm 10 \mathrm{mAh} \mathrm{g}^{-1}(\sim 12 \%)$. It is interesting and surprising that the NALNMO electrodes shows a longer plateau region, which is related to either oxygen loss and/or the oxidation of lattice oxygen, ${ }^{31,32}$ while the observed irreversible capacity decreases.

Parts $\mathrm{b}$ and $\mathrm{c}$ of Figure 3 represent the discharge profiles of both materials subject to different rates, from $12.5(\mathrm{C} / 20)$ to $500 \mathrm{~mA} \mathrm{~g}^{-1}$ (2C); the charge current remained $12.5 \mathrm{~mA} \mathrm{~g}^{-1}$ in 
Table 1. Rietveld Refinement Results of Neutron Diffraction Data for LNMO and NALNMO Powders

\begin{tabular}{lccccc} 
& $a(\AA)$ & $c(\AA)$ & Li/Ni mixing & oxygen coordinates & $R_{\mathrm{p}}(\%)$ \\
LNMO & $2.8615(1)$ & $14.2580(6)$ & $0.037(4)$ & $0,0,0.2417(7)$ & 4.29 \\
NALNMO & $2.8623(1)$ & $14.2621(6)$ & $0.040(4)$ & $0,0,0.2416(7)$ & 3.81 \\
\hline
\end{tabular}
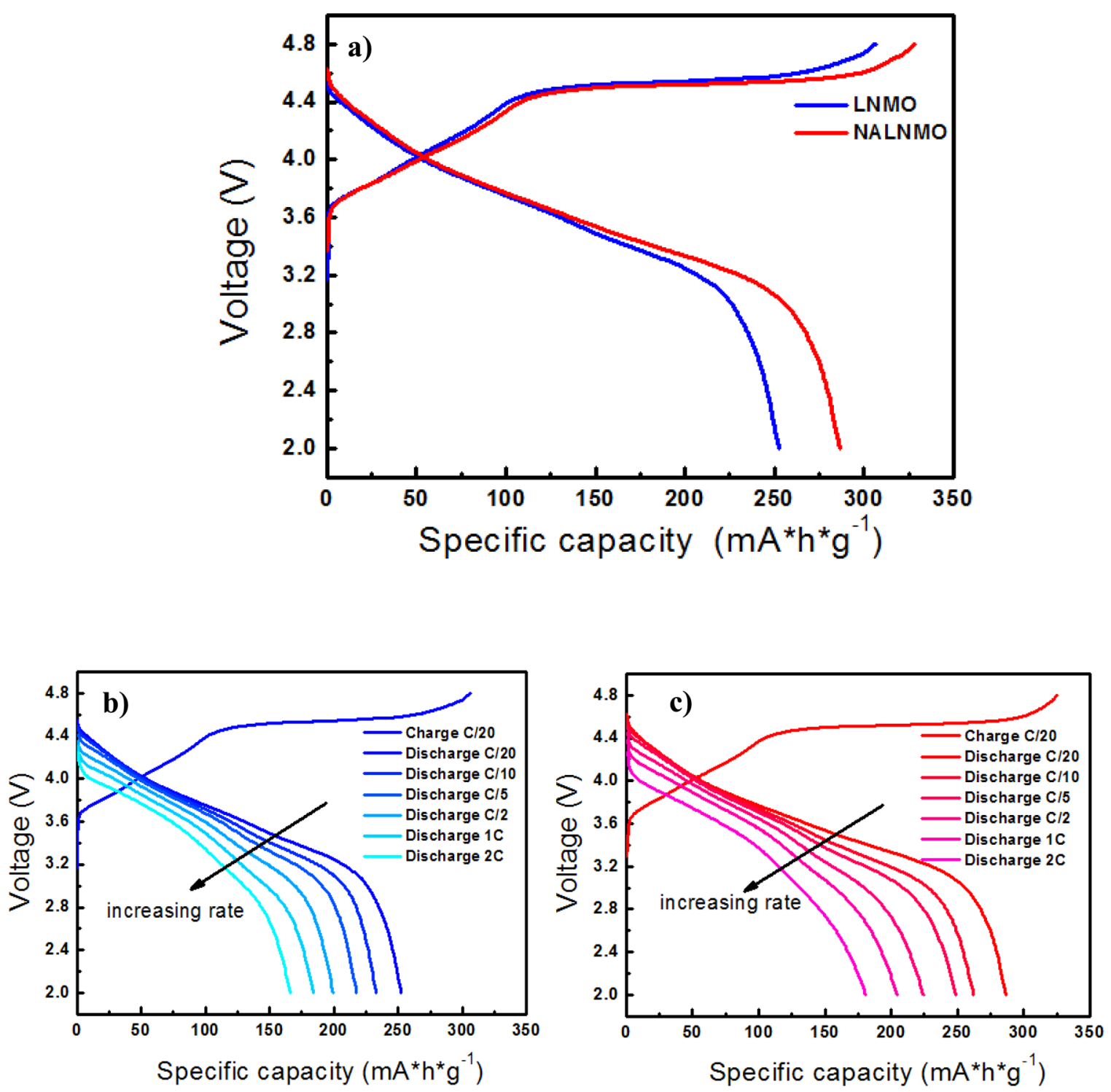

Figure 3. Comparison of electrochemical performances between LNMO and NALNMO: (a) first cycle charge/discharge voltage profile, (b) voltage profile of LNMO under different current density, and (c) voltage profile of NALNMO under different current density. The voltage range is $2.0-4.8$ $\mathrm{V}$ at $1 \mathrm{C}=250 \mathrm{~mA} \mathrm{~g}^{-1}$.

all cases. The NALNMO electrode delivered higher discharge capacity than LNMO at all testing rates. Even at $500 \mathrm{~mA} \mathrm{~g}^{-1}$ current density, the surface modified material still shows a discharge capacity as high as $181 \mathrm{mAh} \mathrm{g}^{-1}$.

The long-term cycling performance of both materials were compared by charging and discharging each at a current density of $25 \mathrm{~mA} \mathrm{~g}^{-1}(\mathrm{C} / 10)$, which is represented in Figure 4. The NALNMO electrode exhibits higher discharge capacity in early cycles but becomes similar to the pristine material after 80 cycles. The capacity difference between the two materials after 80 cycles is only $8 \mathrm{mAh} \mathrm{g}^{-1}$, which is much smaller than the 44 $\mathrm{mAh} \mathrm{g}^{-1}$ of the first cycle. The voltage decay upon cycling exists in both materials but is slightly better in NALNMO, which is described in more detail later.
The discharge voltage profiles and corresponding $\mathrm{d} Q / \mathrm{d} V$ plots of both materials upon cycling are shown in Figure 5. By comparing their $\mathrm{d} Q / \mathrm{d} V$, we can better understand how the capacity and voltage decay occur in each material. From those plots, we can clearly see three peaks during discharge. The first peak is above $4.0 \mathrm{~V}$, the second peak sits between 3.5 and $4.0 \mathrm{~V}$, and the third peak is below $3.5 \mathrm{~V}$. The first and second peaks are a result of $\mathrm{Ni}^{4+}$ to $\mathrm{Ni}^{2+}$, and possible oxygen reduction. ${ }^{32-35}$ The third peak, on the other hand, is considered to be a combination of $\mathrm{Mn}^{4+}$ to $\mathrm{Mn}^{3+}$ and oxygen reduction as a result of $\mathrm{Li}$ insertion back into the bulk structure, as several authors have previously reported. ${ }^{1,3,33,36}$ By comparing Figure 5 b,d, we can see that the third peak area of pristine material is much smaller than that of the modified material. The changes that 

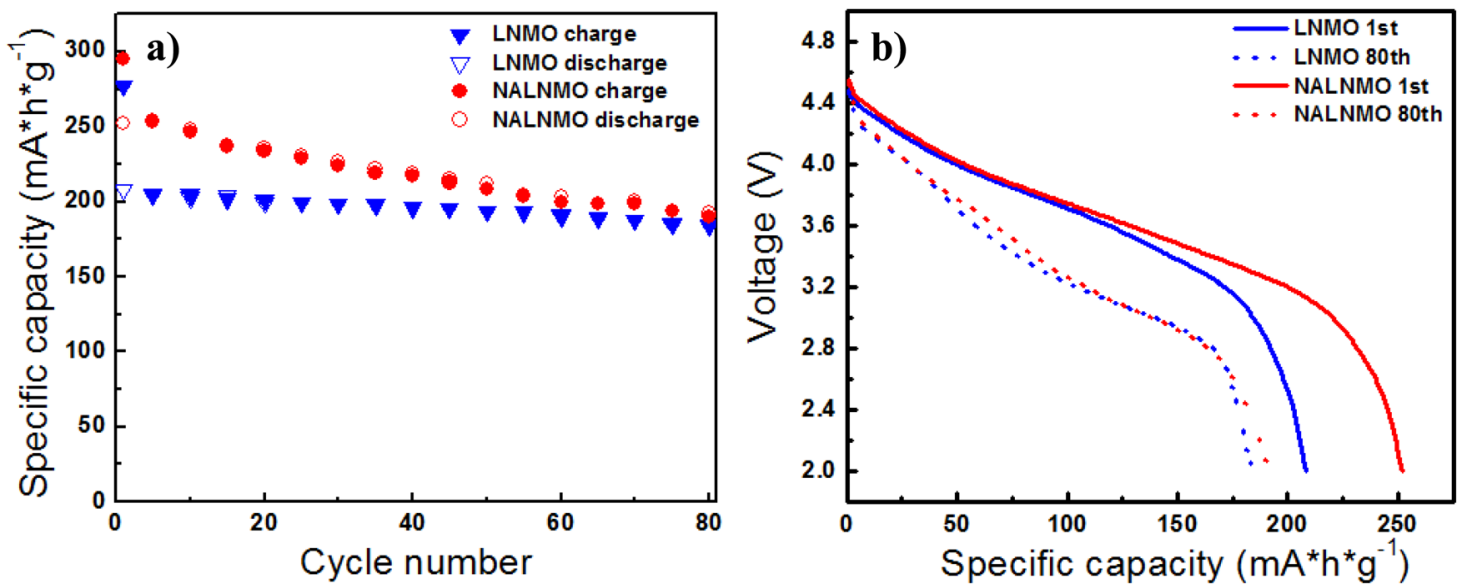

Figure 4. Comparison of (a) capacity and (b) discharge voltage, between LNMO and NALNMO, after 80 cycles. The voltage range is $2.0-4.8 \mathrm{~V}$ at $\mathrm{C} / 10=25 \mathrm{~mA} \mathrm{~g}^{-1}$.
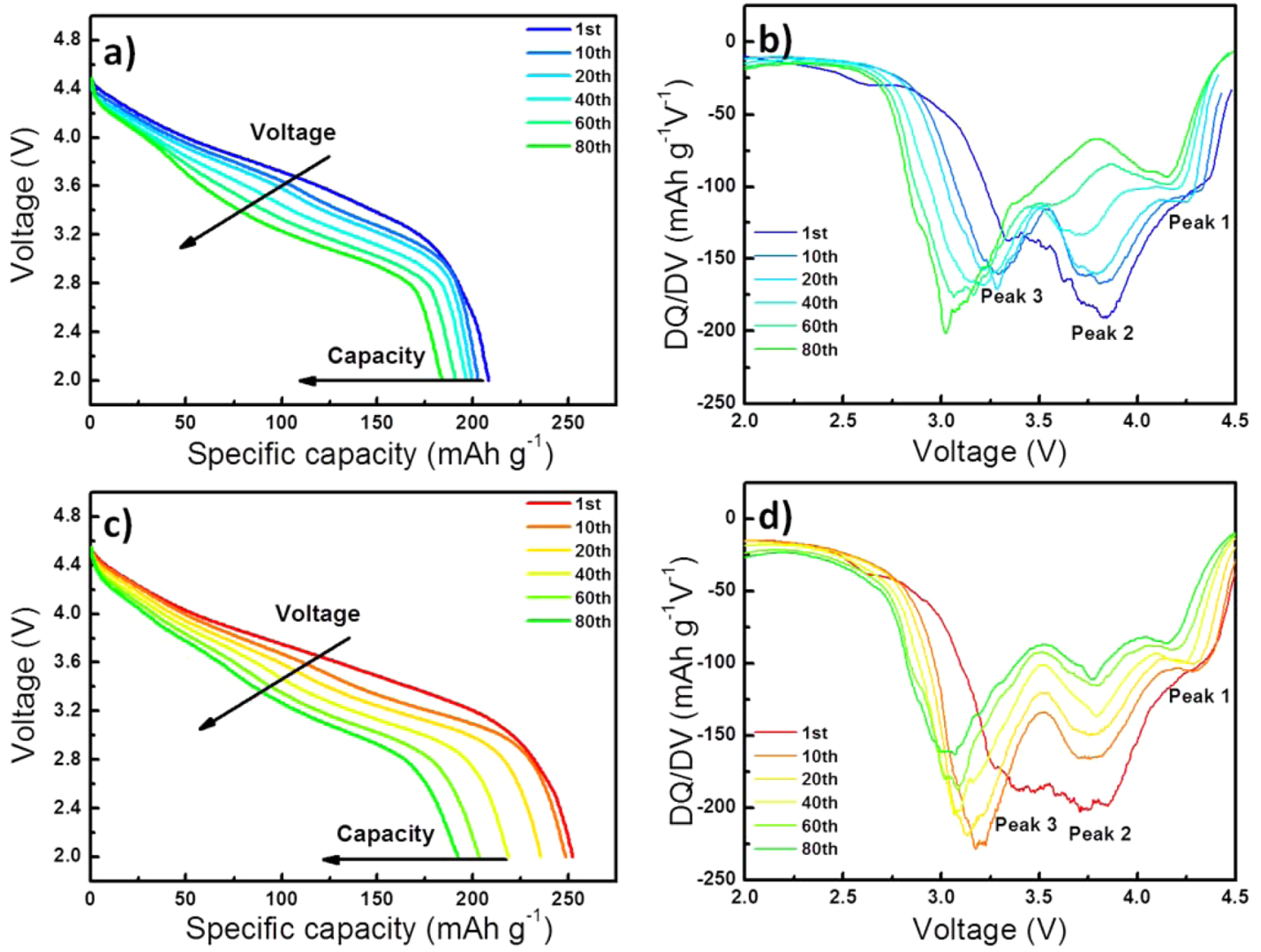

Figure 5. Discharge and corresponding $\mathrm{d} Q / \mathrm{d} V$ profiles of ( $a$ and b) LNMO and (c and d) NALNMO, over the course of 80 cycles.

occur in that peak over 80 cycles are quite distinct for each material as well. Whereas the third peak area of LNMO exhibits a continuous increase during cycling, the NALNMO peak area only increases during the initial 10 cycles. In contrast to the pristine material, the third peak area of modified material continues to decrease after 10 cycles. Another major difference is that the second peak of NALNMO remains relatively stable throughout cycling. Though it decreases in magnitude, its position remains constant. The second peak of LNMO not only decreases in area but also shifts to lower voltage and loses its prominence. The voltage fade in this region is demonstrated in Figure $4 \mathrm{~b}$ as well. The first peak area of LNMO continuously decreases during cycling and shifts toward lower voltage. On the other hand, the peak area of NALNMO increases during the first 10 cycles, then decreases thereafter. Its peak position decreases, but not by as much as LNMO, as it remains much more narrow. The $\mathrm{NH}_{4} \mathrm{~F}$ and $\mathrm{Al}_{2} \mathrm{O}_{3}$ surface co-modification stabilized the first and second peak regions; a detailed understanding of these phenomena will be discussed later.

3.3. Surface Structure and Chemical Species Characterization. Neutron diffraction and SEM analysis demonstrated that the crystal structure and particle morphology of both materials were quite similar; however, they exhibited large differences in electrochemical performance. Advanced techniques, such as HRTEM, a-STEM/EELS, and XPS, were carried 
out to investigate the surface structure and chemistry of both materials in more detail.

High-resolution transmission electron microscopy was used to identify the $\mathrm{Al}_{2} \mathrm{O}_{3}$ coating on surface modified material. Parts $\mathrm{a}$ and $\mathrm{b}$ of Figure 6 present HRTEM images of LNMO and

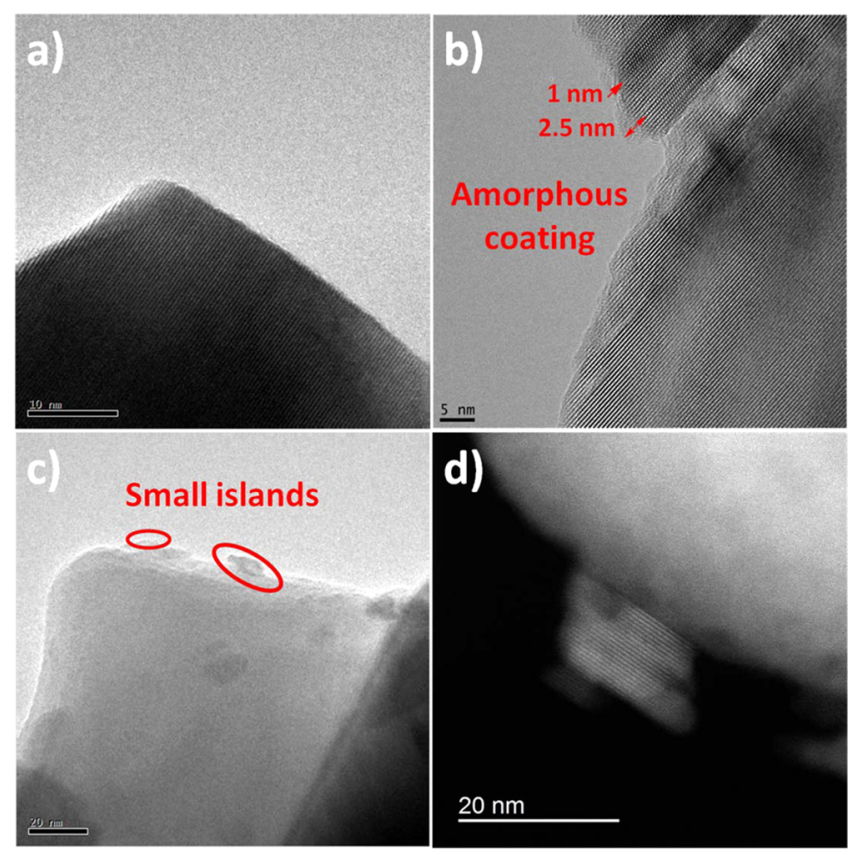

Figure 6. TEM and STEM photographs of LNMO and NALNMO: (a) TEM of LNMO, (b and c) TEM of NALNMO, and (d) STEM of NALNMO.

NALNMO, respectively. The TEM images of both materials show very good layered crystal structure. Amorphous films are observed on the surface of NALNMO, while the LNMO shows a very clean surface. More than 20 particles were analyzed to examine the amorphous film. As shown in Figure $6 \mathrm{~b}$, this amorphous film is unevenly coated on the surface, with thickness ranging from 0 to $2.5 \mathrm{~nm}$. As our recent study indicates, the surface chemistry of LNMO varies with different preparation methods. ${ }^{37}$ We also applied the same $\mathrm{NH}_{4} \mathrm{~F}$ and $\mathrm{Al}_{2} \mathrm{O}_{3}$ surface co-modification on LNMO prepared using a carbonate synthesis method, ${ }^{37}$ and interestingly the formed $\mathrm{Al}_{2} \mathrm{O}_{3}$ coating exhibited a uniform coating of $1 \mathrm{~nm}$ thickness, as shown in SI Figure S2. This shows that surface modifications and treatments have a degree of dependency of the specific synthesis route for even the same materials. It would be of great interest to explore this dependence further. In addition to the amorphous coating, there are isolated nanoislands sitting on the surface of particles, as illustrated in Figure $6 c$, which are not observed in our pristine $\mathrm{Li}_{1.2} \mathrm{Ni}_{0.2} \mathrm{Mn}_{0.6} \mathrm{O}_{2}$. Figure $6 \mathrm{~d}$ depicts the TEM image of these nanoislands at higher magnification. They exhibit a well-layered crystal structure with particle size around $20 \mathrm{~nm}$. EELS was performed on the isolated nanoislands to verify that they were the active material instead of Al-related compounds, as shown in SI Figure S3.

Figure 7 depicts the differences between the bulk and surface structure of NALNMO. Multiple grains were selected for study, and the results were consistent; therefore, only representative data are shown here. Shown in Figure 7a the atomistic surface structure of the NALNMO, however, is distinct from the bulk region, with extra bright spots in the lithium layer. In order to better visualize the difference, fast Fourier transform (FFT) was carried out from both bulk (red square) and surface (blue square) as illustrated. The extra spots in FFT images from the surface (Figure $7 \mathrm{c}$ ) indicate a spinel-like structure compared to the pure layered structure of the bulk (Figure $7 \mathrm{~b}$ ). The atomic model insets in Figure $7 \mathrm{~d}$,e better illustrate the contrast differences. The spinel-like phase on the surface is around $3 \mathrm{~nm}$ thickness after the co-modification.

In addition to direct visualization of the crystal structure changes, EELS was carried out to obtain chemical information. Two representative NALNMO particles were observed and studied. One consists of the $\mathrm{C} 2 / \mathrm{m}$ phase, measured along the $(10 \overline{1})$ zone axis; this electron diffraction pattern is represented by the inset of Figure $8 \mathrm{a}$. The other is $R \overline{3} m$ phase measured along the (010) zone axis, which is presented in Figure 8d. EELS was performed on NALNMO from bulk to surface, using a step size of $\sim 1 \mathrm{~nm}$; the region of analysis is represented by the red rectangles in Figure $8 \mathrm{a}, \mathrm{d}$. The $\mathrm{L}_{3^{-}}$and $\mathrm{L}_{2}$-edges of
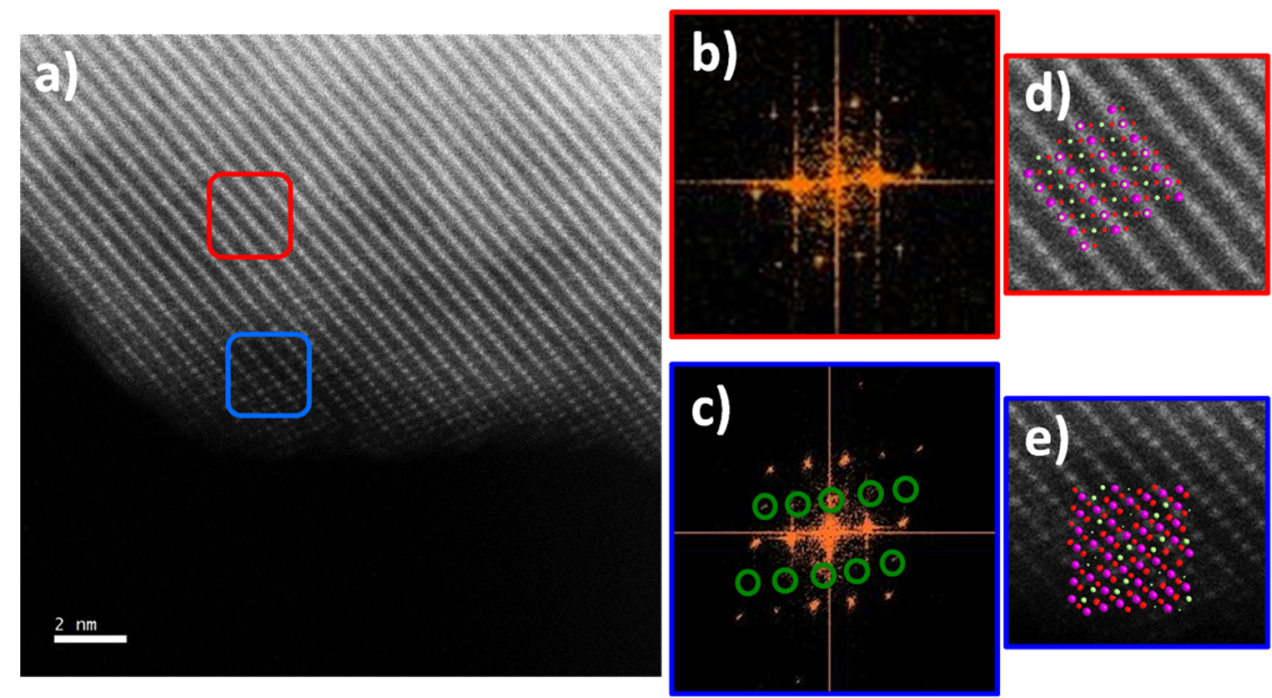

Figure 7. High-resolution STEM images of NALNMO: (a) NALNMO, (d) bulk region, and (e) surface region. Fast Fourier transform (FFT): (b) bulk region and (d) surface region. (The inset crystal structures in $\mathrm{d}$ and e: green, $\mathrm{Li}$; red, O; purple, transition metal). 

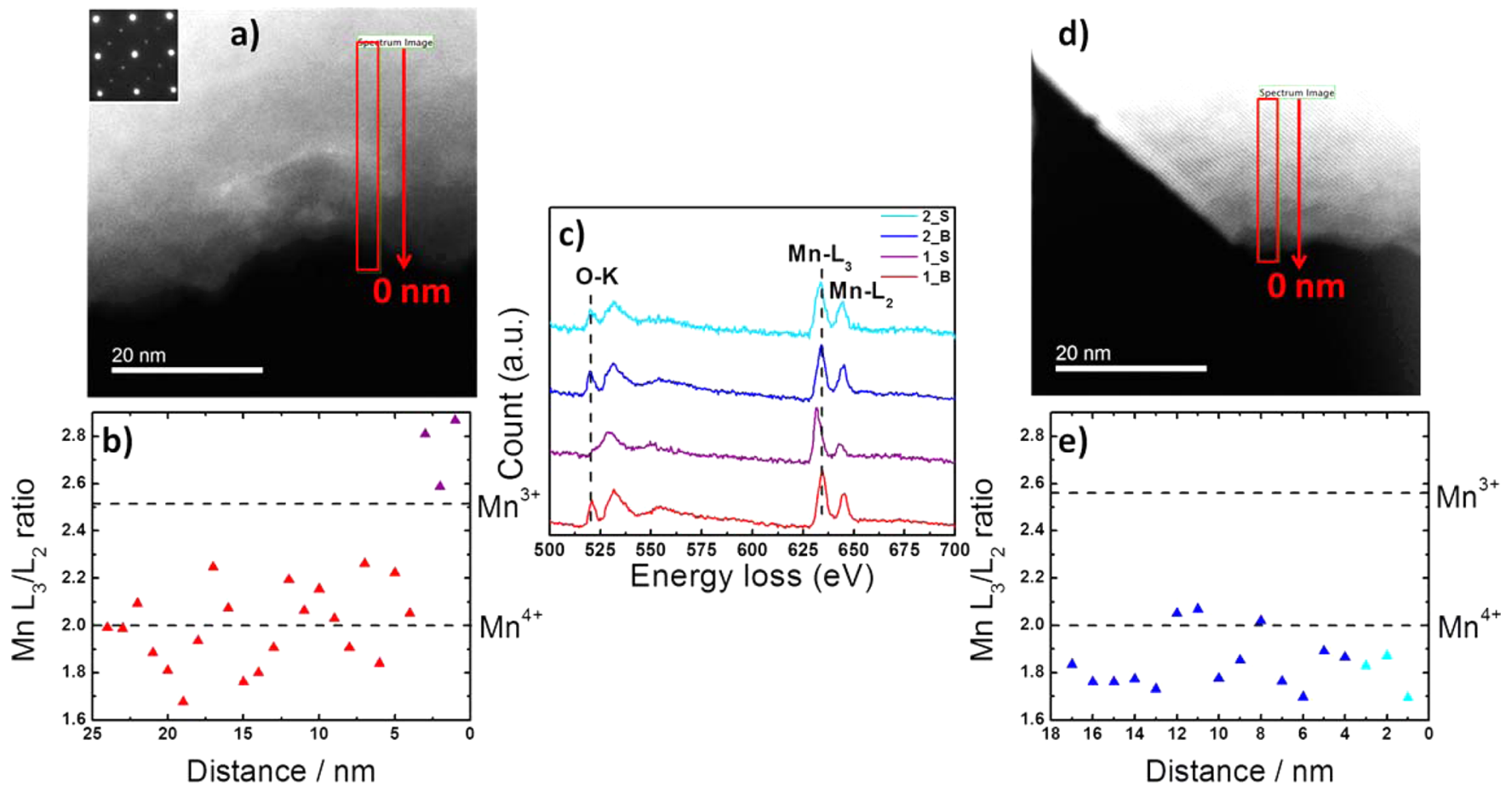

Figure 8. STEM images of NALNMO with step scan of Mn EELS L-edge and O EELS K-edge: (a) STEM of NALNMO with $C 2 / m$ domain, (b) corresponding $\mathrm{Mn} \mathrm{L}_{3} / \mathrm{L}_{2}$ ratio, (c) representative EELS spectra of the Mn L-edge and O K-edge from the surface and bulk of NALNMO with different domains ( 1 is $C 2 / m$ domain particle, 2 is $R \overline{3} m$ domain particle, S represents the surface, and B represents bulk), (d) STEM of NALNMO with $R \overline{3} m$ domain, and (e) corresponding $\mathrm{Mn} \mathrm{L}_{3} / \mathrm{L}_{2}$ ratio.
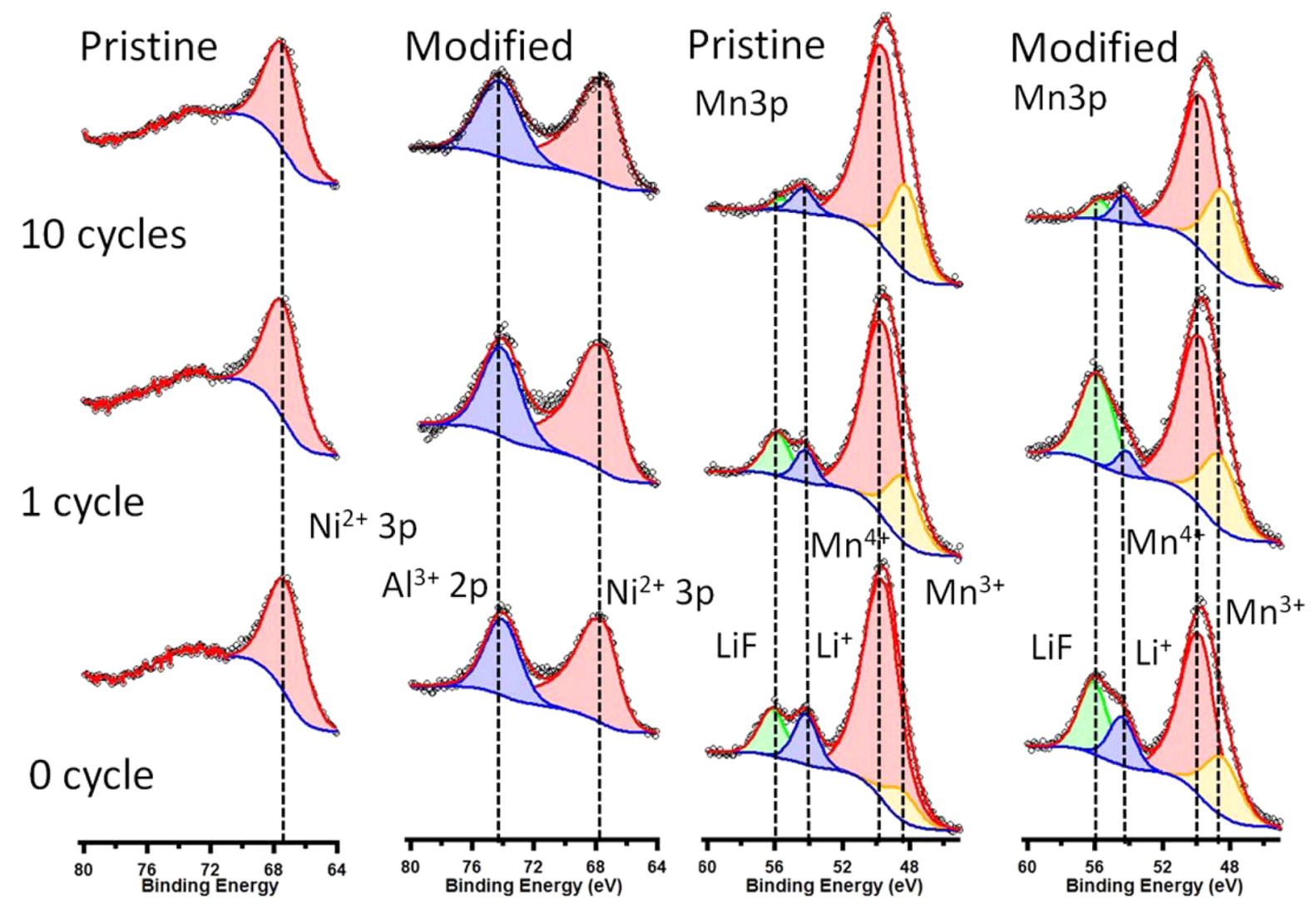

Figure 9. Ni 3p and Mn 3p core level X-ray photoelectron spectra of LNMO and NALNMO at various stages of cycling.

transition metals are due to the electronic excitation from the $2 \mathrm{p}^{3 / 2}$ to $3 \mathrm{~d}^{3 / 2}$ and $3 \mathrm{~d}^{5 / 2}$ orbitals and from the $2 \mathrm{p}^{1 / 2}$ to $3 \mathrm{~d}^{3 / 2}$ orbitals, respectively. Previous studies have shown that the $\mathrm{L}_{3} /$
$\mathrm{L}_{2}$ ratio is sensitive to the valence state of $\mathrm{Mn}^{38,39} \mathrm{The}_{3} / \mathrm{L}_{2}$ ratios, plotted as a function of distance from surface to bulk, are shown in Figure 8 b,e. The $\mathrm{L}_{3} / \mathrm{L}_{2}$-edge ratios of both particles 
reveal that the Mn oxidation state remains $4+$ in the bulk, as it does in pristine LNMO ${ }^{30}$ However, the $C 2 / m$ domain particle (Figure $8 \mathrm{a}$ ) shows $\mathrm{Mn}$ oxidation state reduced to $3+$ within a 3 $\mathrm{nm}$ region of the surface. The corresponding $\mathrm{O}$ K-edge of the bulk and surface are plotted in red and purple, respectively. The prepeak in the $\mathrm{O} \mathrm{K}$-edge is due to the transition of 1 s electrons to the unoccupied $2 \mathrm{p}$ orbitals, which hybridize with the TM $3 \mathrm{~d}$ orbitals. The decrease in the prepeak intensity of the $\mathrm{C} 2 / \mathrm{m}$ domain particle agrees with the evidence that $\mathrm{Mn}$ at the surface is reduced. ${ }^{32}$ The EELS study shows that the surface $\mathrm{Mn}$ in the $\mathrm{C} 2 / \mathrm{m}$ region is getting preactivated.

While STEM-EELS were used to examine small local regions, XPS was performed on soaked and cycled samples in order to investigate the overall chemical changes on the surface upon cycling. Figure 9 shows Ni 3p and Mn 3p XPS spectra of both LNMO and NALNMO after soaking in electrolyte, after one cycle, and after 10 cycles. The Mn 3p peak is composed of two components, with the main signal $\sim 49.7 \mathrm{eV}$ assigned to $\mathrm{Mn}^{4+}$ and a weaker signal at lower binding energy $\sim 48.5 \mathrm{eV}$ related to $\mathrm{Mn}^{3+}{ }^{30}$ The relative percents of these components are given in Table 2. These results illustrate that soaking electrodes in the

Table 2. Summary of Surface $\mathrm{Mn}^{3+}$ Percentage of LNMO and NALNMO at Different Cycle Numbers

\begin{tabular}{|llc} 
& cycle no. & percentage of $\mathrm{Mn}^{3+}(\%)$ \\
\hline \multirow{3}{*}{ LNMO } & noncycled & 10.1 \\
& 1 & 21.6 \\
& 10 & 24.5 \\
& noncycled & 25.8 \\
& 1 & 27.3 \\
& 10 & 31.0 \\
\hline
\end{tabular}

electrolyte will induce the formation of $\mathrm{Mn}^{3+}$, even without charge/discharge. Before cycling, NALNMO shows almost three times more $\mathrm{Mn}^{3+}$ at the surface than LNMO. The degree of $\mathrm{Mn}^{3+}$ is shown to continuously increase upon cycling for both materials. At any given cycle, however, the degree of $\mathrm{Mn}^{3+}$ is consistently greater for modified material, compared to the pristine. SI Figure S4 shows each material's Mn 3s regions. The difference in binding energy between those peaks $(\Delta E$, SI Table $\mathrm{S} 1)$ has been used to approximate the average $\mathrm{Mn}$ oxidation state $(\mathrm{AOS})$ by the equation, $\mathrm{AOS}=8.956-1.126 \Delta E .^{41} \mathrm{SI}$ Figure $S 4$ shows that the peak separation of NALNMO powder is larger than LNMO powder. The calculated approximate average Mn oxidation states for LNMO powder is 4+, while that of NALNMO is $\mathrm{Mn}^{3.74+}$. After 10 cycles, the splitting increases for both LNMO and NALNMO, corresponding to the approximate average oxidation states of $\mathrm{Mn}^{3.36+}$ and $\mathrm{Mn}^{3.17+}$, respectively. The XPS of the $\mathrm{Mn} 3 \mathrm{~s}$ region agrees well with that of the $\mathrm{Mn} 3 \mathrm{p}$ region; both indicate a lower average oxidation state of $\mathrm{Mn}$ at the surface of NALNMO.

The $\mathrm{Li}$ 1s peaks are detected above the $\mathrm{Mn} 3 \mathrm{p}$ region around $55 \mathrm{eV}$. The green peaks at $56 \mathrm{eV}$ correspond to $\mathrm{LiF}$, and the blue peaks at $54.3 \mathrm{eV}$ correspond to $\mathrm{Li}-\mathrm{O}$ in the lattice. ${ }^{42}$ By comparing both soaked electrodes, NALNMO exhibits more $\mathrm{LiF}$ on the surface than pristine LNMO.

All of the $\mathrm{Ni} 3 \mathrm{p}$ peaks sit at a binding energy of $67.5 \mathrm{eV}$, indicating that the oxidation states of surface $\mathrm{Ni}$ ions are $2+{ }^{43}$ This result is expected because the valence of $\mathrm{Ni}$ in the discharged states should be reduced from $\mathrm{Ni}^{4+}$ to $\mathrm{Ni}^{2+}$. The NALNMO shows an extra peak at $74 \mathrm{eV}$, which is assigned to $\mathrm{Al} 2 \mathrm{p}$. The position of this peak suggests that the coating is $\mathrm{Al}^{3+}$ in $\mathrm{Al}_{2} \mathrm{O}_{3}$, as demonstrated by Baggetto et al. ${ }^{40}$ Because the peak does not shift in binding energy through 10 cycles, the amorphous $\mathrm{Al}_{2} \mathrm{O}_{3}$ coating likely remains chemically unaltered on the sample to this point.

\section{DISCUSSION}

4.1. Surface Structural Changes Induced by $\mathrm{NH}_{4} \mathrm{~F}$ and $\mathrm{Al}_{2} \mathrm{O}_{3}$ Co-modification. Based upon the HRTEM and aSTEM/EELS results reported here, the surface of layered LNMO transforms to a spinel-like structure after $\mathrm{NH}_{4} \mathrm{~F}$ and $\mathrm{Al}_{2} \mathrm{O}_{3}$ surface co-modification. This spinel-like phase is induced by the weak acid treatment of $\mathrm{NH}_{4} \mathrm{~F}$ during surface
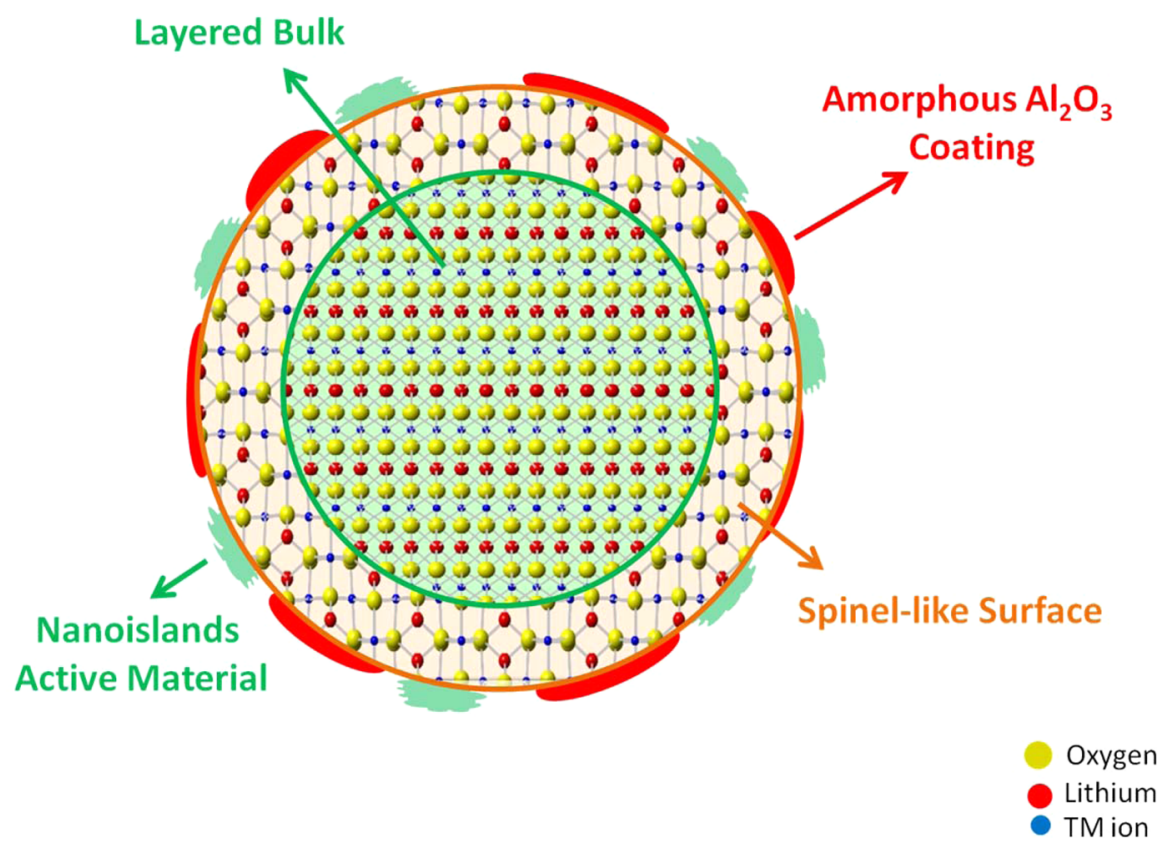

Figure 10. Schematic of proposed structure model of NALNMO (not drawn to scale). 
modification, as reported previously by Sun et al. ${ }^{44}$ Here, we propose the reaction eq 1 to describe its formation; the value of $x$ is very small and is theoretically less than 0.0038 .

$$
\begin{aligned}
& \mathrm{Li}_{1.2} \mathrm{Ni}_{0.2} \mathrm{Mn}_{0.6} \mathrm{O}_{2}+8 x \mathrm{NH}_{4} \mathrm{~F}+4 x \mathrm{H}_{2} \mathrm{O} \\
& \leftrightharpoons \\
& \quad(1-x) \mathrm{Li}_{1.2} \mathrm{Ni}_{0.2} \mathrm{Mn}_{0.6} \mathrm{O}_{2} \cdot 0.4 x\left(\mathrm{LiNi}_{0.5} \mathrm{Mn}_{1.5} \mathrm{O}_{4}\right) \\
& \quad+8 x \mathrm{LiF}+8 x \mathrm{NH}_{4} \mathrm{OH}
\end{aligned}
$$

Before electrochemical cycling, NALNMO exhibits more LiF at the surface, which supports the reaction previously proposed. Besides the formation of a spinel-like structure, nanoislands of active material were observed at the surface as well. Their presence may be the result of being etched away from the bulk by the $\mathrm{NH}_{4} \mathrm{~F}$ surface modification treatment.

In addition, nonuniform amorphous coatings have been observed by HRTEM. The XPS results indicate that the binding energy of $\mathrm{Al} 2 \mathrm{p}$ is $74 \mathrm{eV}$, which is the typical binding energy of $\mathrm{Al}_{2} \mathrm{O}_{3}$. This finding is supported by the study by Rosina et al., which proposes that the surface coating of $\mathrm{AlF}_{3}$ is actually $\mathrm{AlO}_{x} \mathrm{~F}_{y}{ }^{45}$ The $\mathrm{Al}-\mathrm{O}$ bond was shown to preferentially form when the active material possesses surface hydroxides, which was likely the case for our hydroxide co-precipitated material.

We propose that the $\mathrm{Al}\left(\mathrm{NO}_{3}\right)_{3} \cdot 9 \mathrm{H}_{2} \mathrm{O}$ used in the surface modification process hydrolyzed directly; reaction eq 2 presents this process.

$$
2 \mathrm{Al}\left(\mathrm{NO}_{3}\right)_{3}+6 \mathrm{NH}_{4} \mathrm{OH} \leftrightharpoons \mathrm{Al}_{2} \mathrm{O}_{3}+6 \mathrm{NH}_{4} \mathrm{NO}_{3}+3 \mathrm{H}_{2} \mathrm{O}
$$

Based on the preceding discussion, a schematic structure model of NALNMO is depicted in Figure 10. A summary description of the proposed model possesses several unique attributes: (1) the spinel-like structure forms around the layered material's surface, with $3 \mathrm{~nm}$ thickness; (2) the amorphous coating exists on the outermost exterior and consists of amorphous $\mathrm{Al}_{2} \mathrm{O}_{3}$, as identified using TEM and XPS; (3) nanoislands $(<20 \mathrm{~nm})$ exist on the surface as well, which arise from modification treatment.

4.2. Origin of Improved Electrochemical Performance after $\mathrm{NH}_{4} \mathrm{~F}$ and $\mathrm{Al}_{2} \mathrm{O}_{3}$ Surface Co-modification. One related question raised in previous sections is, why does NALNMO exhibit a longer charge plateau but less irreversible capacity? In fact it exhibited a $34 \mathrm{mAh} \mathrm{g}^{-1}$ larger discharge capacity overall. After all $\mathrm{Ni}$ ions are fully oxidized after the slope region from 3.7 to $4.4 \mathrm{~V}$, the plateau at $4.5 \mathrm{~V}$ is believed to originate from $\mathrm{Li}^{+}$being extracted from the structure and accompanied by the oxidation of lattice oxygen. Armstrong et al. observed that oxygen leaves the structure in the form of $\mathrm{O}_{2}$ gas by using in situ differential electrochemical mass spectrometry (DEMS). ${ }^{31} \mathrm{Hy}$ et al. proposed the formation of $\mathrm{Li}_{2} \mathrm{O}$ and $\mathrm{Li}_{2} \mathrm{CO}_{3}$ during the plateau region as a result of oxygen evolution, using surface enhanced Raman spectroscopy (SERS). ${ }^{33}$ Koga et al. and Sathiya et al. claimed that lattice $\mathrm{O}^{(2-\delta)-} / \mathrm{O}^{2-}$ is activated during charge and discharge. ${ }^{46,47}$ The notably longer plateau exhibited by NALNMO may likely be caused by the nanoislands active material introduced during surface modification. Due to nanosizing, these nanoislands may show improved diffusion kinetics as well as a higher propensity to activation during electrochemical cycling. This enhanced activation may be reflected in the first cycle charge profile, which exhibits a longer plateau region compared to the LNMO material.
The amorphous $\mathrm{Al}_{2} \mathrm{O}_{3}$ surface coating likely acts as protective layer to prevent side reactions between electrode and electrolyte, as well as to limit the irreversible loss of oxygen, as proposed by Zheng et al. and Koga et al. ${ }^{7,34}$ This layer may, therefore, contribute to the improved irreversible capacity loss observed in the first cycle electrochemical profile. It should be noted that this protective layer was not observed on the surface nanoislands, which may contribute to the capacity fading observed for NALNMO.

Though there is only a simple slope observed during discharge, the $\mathrm{d} Q / \mathrm{d} V$ plot shows it to be a complex multiplereaction process. Because the capacity during discharge is always larger than the capacity theoretically possible by the $\mathrm{Ni}^{4+}$ to $\mathrm{Ni}^{2+}$ reduction reaction, many efforts have been made to describe the reversibility of oxygen reduction in order to explain the extra capacity. ${ }^{32,33,35,46}$ Some groups suggest that the extra capacity also originates from the $\mathrm{Mn}^{4+}$ to $\mathrm{Mn}^{3+}$ reduction reaction. ${ }^{3,48}$ LNMO and NALNMO respectively show 148 and $159 \mathrm{mAh} \mathrm{g}^{-1}$ discharge capacity above $3.5 \mathrm{~V}$, which is larger than the $126 \mathrm{mAh} \mathrm{g}^{-1}$ possible from theoretical redox of $\mathrm{Ni}^{2+}$ / $\mathrm{Ni}^{4+}$. This may indicate that a higher degree of reversibility of the oxygen redox pair reaction happens for the NALNMO above $3.5 \mathrm{~V}$ during discharge in comparison to the LNMO. The discharge capacities below $3.5 \mathrm{~V}$ are 105 and $128 \mathrm{mAh} \mathrm{g}^{-1}$ for LNMO and NALNMO, respectively. Considering the longer plateau during charge and more $\mathrm{Mn}^{3+}$ after one cycle observed in surface modified material and the stabilization of the second peak in the $\mathrm{d} Q / \mathrm{d} V$ curve, this capacity difference may arise from the preactivated and electrochemically activated surface $\mathrm{Mn}$ allowing for some $\mathrm{Mn}^{3+} / \mathrm{Mn}^{4+}$ redox pair reaction and higher degree of reversibility for the oxygen redox pair reaction. In summary, the origin of the improved discharge capacity by $\mathrm{NH}_{4} \mathrm{~F}$ and $\mathrm{Al}_{2} \mathrm{O}_{3}$ surface co-modification may consist of decreased irreversible oxygen loss, a higher degree of reversibility for the oxygen redox pair reaction, facilitating the activation of cathode material, and preactivating of the surface leading to more $\mathrm{Mn}^{3+}$.

As described previously, NALNMO exhibits higher discharge capacity in early cycles but becomes closer to the pristine sample after 80 cycles. For the third peak region, both materials show increasing capacity upon the 10th cycle; the increasing $\mathrm{Mn}^{3+}$ content from the first cycle to 10th cycle at surface of both materials detected by XPS is an indication for the increased participation of $\mathrm{Mn}^{3+} / \mathrm{Mn}^{4+}$ redox pair. A stark difference was found for the second peak regions in the $\mathrm{d} Q / \mathrm{d} V$ plot where the second peaks of LNMO shift by a large degree driving the Ni-redox process to lower potential and becoming indiscernible, possibly destabilizing the LNMO. In contrast, while NALNMO shows a decrease in the intensity of the second peak, the apex of the peak maintains its potential position and is still prevalent after the 80th cycle. Both the first and third peaks have been associated with oxygen reduction, and the latter specifically to manganese reduction. For NALNMO, due to possibly preactivation, the manganese and oxygen redox occurs on the onset of early cycles while LNMO is mostly dominated by these reactions in later cycles. While NALMNO shows capacity decrease, the reduction process of $\mathrm{Ni}^{4+}$ to $\mathrm{Ni}^{2+}$ remains relatively constant, maintaining the longterm stability of this material.

Besides the capacity degradation, both materials suffer from voltage decay upon cycling. The three peaks in the $\mathrm{d} Q / \mathrm{d} V$ plots were fit using separate Gaussian functions in order to determine the position of each peak. The third peak of both materials 
shifted to $\sim 3.0 \mathrm{~V}$ after 80 cycles, which is $0.3 \mathrm{~V}$ lower than their first cycle. The changes in position of the first and second peaks revealed different trends in both materials upon cycling. The second peak of LNMO lowered by $\sim 0.4 \mathrm{~V}$, while the same peak of NALNMO decreased by only $\sim 0.1 \mathrm{~V}$. There is a $\sim 0.2 \mathrm{~V}$ shift of the first peak to lower voltage for LNMO, but only $\sim 0.1$ $\mathrm{V}$ for the NALNMO. Based upon analysis of the $\mathrm{d} Q / \mathrm{d} V$ plots and surface characterization of pristine and surface modified materials, we can draw the conclusion that the $\mathrm{NH}_{4} \mathrm{~F}$ and $\mathrm{Al}_{2} \mathrm{O}_{3}$ surface co-modification partly stabilized the first and second peak regions, in terms of capacity and voltage, but the third peak region continues to show degradation upon cycling.

This detailed study of the role of $\mathrm{NH}_{4} \mathrm{~F}$ and $\mathrm{Al}_{2} \mathrm{O}_{3}$ surface comodification suggests that each treatment during the modification process can dramatically transform the materials' surface structure and chemistry. Those changes have contributed to the electrochemical performance of the final samples from different aspects. Adding mild acid introduced the surface spinel-like structure and etched nanoislands formations, which will facilitate the activation of the cathode material, leading to a higher discharge capacity. An amorphous surface coating reduced the direct reaction between electrode and electrolyte, resulting in less irreversible oxygen loss. More surface modification works are undergoing study in order to discover an ideal surface modification method.

\section{CONCLUSION}

In this work, we reveal that the surface chemistry of cathode materials will significantly affect the uniformity and chemistry of coating layer. The surface co-modifications brought changes to the material's surface, from both a structural and chemical aspect. In order to identify these sophisticated changes, multimodality surface sensitive tools were applied in an attempt to obtain a complete picture. $\mathrm{NH}_{4} \mathrm{~F}$ promoted the transformation of a surface spinel-like phase, as well as the formation of isolated nanoislands of active material, which facilitated the activation of the cathode material, leading to higher discharge capacity. At the same time, amorphous $\mathrm{Al}_{2} \mathrm{O}_{3}$ surface coating reduced the side reaction between electrode and electrolyte, and also irreversible oxygen loss, thus reducing the irreversible capacity. In particular, while the $\mathrm{Mn}^{3+} / \mathrm{Mn}^{4+}$ redox pair still showed an increase indicating destabilization, the surface comodification stabilized the $\mathrm{Ni}^{2+} / \mathrm{Ni}^{4+}$ region in terms of capacity and voltage. The fundamental understandings of this work not only may be widely used to explain the role of other surface modifications used for high-voltage-cathode materials but also could guide us in designing better cathode materials with higher energy density.

\section{ASSOCIATED CONTENT}

\section{S Supporting Information}

The Supporting Information is available free of charge on the ACS Publications website at DOI: 10.1021/acsami.5b04932.

EDS spectrum of NALNMO starting material, TEM photographs of pristine NALNMO prepared from carbonate method, EELS spectrum of crystalline nanoislands at the surface of NALNMO. XPS Mn 3s regions of LNMO and NALNMO pristine and cycled electrode materials, and XPS Mn 3s region peak separations of LNMO and NALNMO pristine and cycled electrode materials (PDF)

\section{AUTHOR INFORMATION}

\section{Corresponding Author}

*E-mail: shmeng@ucsd.edu.

\section{Notes}

The authors declare no competing financial interest.

\section{ACKNOWLEDGMENTS}

UCSD's efforts are supported by the Assistant Secretary for Energy Efficiency and Renewable Energy, Office of Vehicle Technologies of the U.S. Department of Energy (DOE) under Contract No. DE-AC02-05CH11231, Subcontract No. 7073923, under the Advanced Battery Materials Research (BMR) Program. The neutron experiments benefited from the SNS user facility, sponsored by the office of Basic Energy Sciences (BES), the Office of Science of the DOE. H.L. acknowledges the financial support from the China Scholarship Council under Award No. 2011631005 . Y.C., L.B., and G.M.V. acknowledge the support from U.S. DOE's Office of Basic Energy Sciences, Material Science and Engineering Division. A portion of the TEM was performed at the UCSD CryoElectron Microscopy Facility. The STEM/EELS work was carried out through a user project, supported by ORNL's Center for Nanophase Materials Sciences (CNMS), which is sponsored by the Scientific User Facilities Division, Office of Basic Energy Sciences, U.S. DOE.

\section{ABBREVIATIONS}

a-STEM, aberration-corrected scanning transmission electron microscopy

EELS, electron energy loss spectroscopy

HRTEM, high-resolution transmission electron microscopy LNMO, $\mathrm{Li}_{1.2} \mathrm{Ni}_{0.2} \mathrm{Mn}_{0.6} \mathrm{O}_{2}$

NALNMO, $\mathrm{NH}_{4} \mathrm{~F}$ and $\mathrm{Al}_{2} \mathrm{O}_{3}$ surface co-modified $\mathrm{Li}$ excess $\mathrm{ND}$, neutron diffraction

XPS, X-ray photoelectron spectroscopy

\section{REFERENCES}

(1) Thackeray, M. M.; Kang, S. H.; Johnson, C. S.; Vaughey, J. T.; Benedek, R.; Hackney, S. A. $\mathrm{Li}_{2} \mathrm{MnO}_{3}$-Stabilized $\mathrm{LiMO}_{2}(\mathrm{M}=\mathrm{Mn}, \mathrm{Ni}$, Co) Electrodes for Lithium-ion Batteries. J. Mater. Chem. 2007, 17, 3112-3125.

(2) Ohzuku, T.; Makimura, Y. Layered Lithium Insertion Material of $\mathrm{LiCo}_{1 / 3} \mathrm{Ni}_{1 / 3} \mathrm{Mn}_{1 / 3} \mathrm{O}_{2}$ for Lithium-ion Batteries. Chem. Lett. 2001, 1, 642-643.

(3) Lu, Z. H.; Dahn, J. R. Understanding the Anomalous Capacity of $\mathrm{Li} / \mathrm{Li}\left[\mathrm{NixLi}_{(1 / 3-2 \mathrm{x} / 3)} \mathrm{Mn}_{(2 / 3-\mathrm{x} / 3}\right] \mathrm{O}_{2}$ Cells Using In Situ X-ray Diffraction and Electrochemical Studies. J. Electrochem. Soc. 2002, 149, A815A822.

(4) Lin, F.; Markus, I. M.; Nordlund, D.; Weng, T.-C.; Asta, M. D.; Xin, H. L.; Doeff, M. M. Surface Reconstruction and Chemical Evolution of Stoichiometric Layered Cathode Materials for LithiumIon Batteries. Nat. Commun. 2014, 5, 3529.

(5) Yu, H. J.; Zhou, H. S. High-Energy Cathode Materials $\left(\mathrm{Li}_{2} \mathrm{MnO}_{3}\right.$ $\mathrm{LiMO}_{2}$ ) for Lithium-Ion Batteries. J. Phys. Chem. Lett. 2013, 4, 12681280.

(6) Robertson, A. D.; Bruce, P. G. Overcapacity of Li$\left[\mathrm{Ni}_{\mathrm{x}} \mathrm{Li}_{1 / 3-2 \mathrm{x} / 3} \mathrm{Mn}_{2 / 3-\mathrm{x} / 3}\right] \mathrm{O}_{2}$ Electrodes. Electrochem. Solid-State Lett. 2004, 7, A294-A298.

(7) Zheng, J. M.; Zhang, Z. R.; Wu, X. B.; Dong, Z. X.; Zhu, Z.; Yang, Y. The Effects of $\mathrm{AlF}_{3}$ Coating on the Performance of Li$\left[\mathrm{Li}_{0.2} \mathrm{Mn}_{0.54} \mathrm{Ni}_{0.13} \mathrm{Co}_{0.13}\right] \mathrm{O}_{2}$ Positive Electrode Material for LithiumIon Battery. J. Electrochem. Soc. 2008, 155, A775-A782. 
(8) Wu, Y.; Manthiram, A. Effect of Surface Modifications on the Layered Solid Solution Cathodes (1- $\mathrm{z}) \mathrm{Li}\left[\mathrm{Li}_{1 / 3} \mathrm{Mn}_{2 / 3}\right] \mathrm{O}_{2}-(\mathrm{z}) \mathrm{Li}-$ $\left[\mathrm{Mn}_{0.5-\mathrm{y}} \mathrm{Ni}_{0.5-\mathrm{y}} \mathrm{Co}_{2 \mathrm{y}}\right] \mathrm{O}_{2}$. Solid State Ionics 2009, 180, 50-56.

(9) Zheng, J. M.; Li, J.; Zhang, Z. R.; Guo, X. J.; Yang, Y. The Effects of $\mathrm{TiO} 2$ Coating on the Electrochemical Performance of $\mathrm{Li}$ $\left[\mathrm{Li}_{0.2} \mathrm{Mn}_{0.54} \mathrm{Ni}_{0.13} \mathrm{Co}_{0.13}\right] \mathrm{O}_{2}$ Cathode Material for Lithium-ion Battery. Solid State Ionics 2008, 179, 1794-1799.

(10) Liu, J.; Wang, Q.; Reeja-Jayan, B.; Manthiram, A. CarbonCoated High Capacity Layered $\mathrm{Li}\left[\mathrm{Li}_{0.2} \mathrm{Mn}_{0.54} \mathrm{Ni}_{0.13} \mathrm{Co}_{0.13}\right] \mathrm{O}_{2}$ Cathodes. Electrochem. Commun. 2010, 12, 750-753.

(11) Liu, J.; Reeja-Jayan, B.; Manthiram, A. Conductive Surface Modification with Aluminum of High Capacity Layered Li$\left[\mathrm{Li}_{0.2} \mathrm{Mn}_{0.54} \mathrm{Ni}_{0.13} \mathrm{Co}_{0.13}\right] \mathrm{O}_{2}$ Cathodes. J. Phys. Chem. C 2010, 114, 9528-9533.

(12) Martha, S. K.; Nanda, J.; Kim, Y.; Unocic, R. R.; Pannala, S.; Dudney, N. J. Solid Electrolyte Coated High Voltage Layered-Layered Lithium-Rich Composite Cathode: $\mathrm{Li}_{1.2} \mathrm{Mn}_{0.525} \mathrm{Ni}_{0.175} \mathrm{Co}_{0.1} \mathrm{O}_{2}$. J. Mater. Chem. A 2013, 1, 5587-5595.

(13) Fu, Q.; Du, F.; Bian, X.; Wang, Y.; Yan, X.; Zhang, Y.; Zhu, K.; Chen, G.; Wang, C.; Wei, Y. Electrochemical Performance and Thermal Stability of $\mathrm{Li}_{1.18} \mathrm{Co}_{0.15} \mathrm{Ni}_{0.15} \mathrm{Mn}_{0.52} \mathrm{O}_{2}$ Surface Coated with the Ionic Conductor $\mathrm{Li}_{3} \mathrm{VO}_{4}$. J. Mater. Chem. A 2014, 2, 7555-7562.

(14) Kang, S.-H.; Thackeray, M. M. Enhancing the Rate Capability of High Capacity $\mathrm{xLi}_{2} \mathrm{MnO}_{3} \cdot(1-\mathrm{x}) \mathrm{LiMO}_{2}(\mathrm{M}=\mathrm{Mn}, \mathrm{Ni}, \mathrm{Co})$ Electrodes by $\mathrm{Li}-\mathrm{Ni}-\mathrm{PO}_{4}$ Treatment. Electrochem. Commun. 2009, 11, 748-751.

(15) Li, J. C.; Baggetto, L.; Martha, S. K.; Veith, G. M.; Nanda, J.; Liang, C. D.; Dudney, N. J. An Artificial Solid Electrolyte Interphase Enables the Use of a $\mathrm{LiNi}_{0.5} \mathrm{Mn}_{1.5} \mathrm{O}_{4} 5 \mathrm{~V}$ Cathode with Conventional Electrolytes. Adv. Energy. Mater. 2013, 3, 1275-1278.

(16) Kim, I. T.; Knight, J. C.; Celio, H.; Manthiram, A. Enhanced Electrochemical Performances of Li-rich Layered Oxides by Surface Modification with Reduced Graphene Oxide/AlPO4 Hybrid Coating. J. Mater. Chem. A 2014, 2, 8696-8704.

(17) Kang, S. H.; Thackeray, M. M. Stabilization of $\mathrm{xLi}_{2} \mathrm{MnO}_{3} \cdot(1-$ $\mathrm{x}) \mathrm{LiMO}_{2}$ Electrode Surfaces ( $\left.\mathrm{M}=\mathrm{Mn}, \mathrm{Ni}, \mathrm{Co}\right)$ with Mildly Acidic, Fluorinated Solutions. J. Electrochem. Soc. 2008, 155, A269-A275.

(18) Fell, C. R.; Carroll, K. J.; Chi, M.; Meng, Y. S. SynthesisStructure-Property Relations in Layered, "Li-excess" Oxides Electrode Materials $\mathrm{Li}\left[\mathrm{Li}_{1 / 3-2 \mathrm{x} / 3} \mathrm{Ni}_{\mathrm{x}} \mathrm{Mn}_{2 / 3-\mathrm{x} / 3}\right] \mathrm{O}_{2}(\mathrm{x}=1 / 3,1 / 4$, and $1 / 5)$. $J$. Electrochem. Soc. 2010, 157, A1202-A1211.

(19) Liu, H. D.; Fell, C. R; An, K.; Cai, L.; Meng, Y. S. In-situ Neutron Diffraction Study of the $\mathrm{xLi}_{2} \mathrm{MnO}_{3} \cdot(1-\mathrm{x}) \mathrm{LiMO}_{2}(\mathrm{x}=0,0.5$; $\mathrm{M}=\mathrm{Ni}, \mathrm{Mn}, \mathrm{Co}$ ) Layered Oxide Compounds During Electrochemical Cycling. J. Power Sources 2013, 240, 772-778.

(20) An, K.; Skorpenske, H. D.; Stoica, A. D.; Ma, D.; Wang, X.-L.; Cakmak, E. First In Situ Lattice Strains Measurements Under Load at VULCAN. Metall. Mater. Trans. A 2011, 42, 95-99.

(21) An, K.; Wang, X. L.; Stoica, A. D. Vulcan Data Reduction and Interactive Visualization Software, ORNL Report ORNL-TM-2012-621; Oak Ridge National Laboratory: Oak Ridge, TN, USA, 2012.

(22) Larson, A. C.; Von Dreele, R. B. General Structure Analysis System (GSAS), Los Alamos National Laboratory Report LAUR 86748; Los Alamos National Laboratory: Los Alamos, NM, USA, 2004.

(23) Toby, B. H. EXPGUI, a Graphical User Interface for GSAS. J. Appl. Crystallogr. 2001, 34, 210-213.

(24) Pennycook, S. J. Z-Contrast Stem for Materials Science. Ultramicroscopy 1989, 30, 58-69.

(25) James, E. M.; Browning, N. D. Practical Aspects of Atomic Resolution Imaging and Analysis in STEM. Ultramicroscopy 1999, 78, 125-139.

(26) Wang, Z. L.; Yin, J. S.; Jiang, Y. D. EELS Analysis of Cation Valence States and Oxygen Vacancies in Magnetic Oxides. Micron 2000, 31, 571-580.

(27) Cai, L.; Liu, Z. C.; An, K.; Liang, C. D. Probing Li-Ni Cation Disorder in $\mathrm{Li}_{1-\mathrm{x}} \mathrm{Ni}_{1+\mathrm{x}-\mathrm{y}} \mathrm{Al}_{\mathrm{y}} \mathrm{O}_{2}$ Cathode Materials by Neutron Diffraction. J. Electrochem. Soc. 2012, 159, A924-A928.

(28) Meng, Y. S.; Ceder, G.; Grey, C. P.; Yoon, W. S.; Jiang, M.; Breger, J.; Shao-Horn, Y. Cation Ordering in Layered O3 Li-
$\left[\mathrm{Ni}_{\mathrm{x}} \mathrm{Li}_{1 / 3-2 \mathrm{x} / 3} \mathrm{Mn}_{2 / 3-\mathrm{x} / 3}\right] \mathrm{O}_{2}(0 \leq x \leq 1 / 2)$ Compounds. Chem. Mater. 2005, 17, 2386-2394.

(29) Breger, J.; Jiang, M.; Dupre, N.; Meng, Y. S.; Shao-Horn, Y.; Ceder, G.; Grey, C. P. High-resolution X-ray Diffraction, DIFFaX, $\mathrm{NMR}$ and First Principles Study of Disorder in the $\mathrm{Li}_{2} \mathrm{MnO}_{3}$ $\mathrm{Li}\left[\mathrm{Ni}_{1 / 2} \mathrm{Mn}_{1 / 2}\right] \mathrm{O}_{2}$ Solid Solution. J. Solid State Chem. 2005, 178, 2575-2585.

(30) Fell, C. R.; Qian, D. N.; Carroll, K. J.; Chi, M. F.; Jones, J. L.; Meng, Y. S. Correlation Between Oxygen Vacancy, Microstrain, and Cation Distribution in Lithium-Excess Layered Oxides During the First Electrochemical Cycle. Chem. Mater. 2013, 25, 1621-1629.

(31) Armstrong, A. R.; Holzapfel, M.; Novak, P.; Johnson, C. S.; Kang, S. H.; Thackeray, M. M.; Bruce, P. G. Demonstrating Oxygen Loss and Associated Structural Reorganization in the Lithium Battery Cathode $\mathrm{Li}\left[\mathrm{Ni}_{0.2} \mathrm{Li}_{0.2} \mathrm{Mn}_{0.6}\right] \mathrm{O}_{2}$. J. Am. Chem. Soc. 2006, 128, 86948698.

(32) Carroll, K. J.; Qian, D.; Fell, C.; Calvin, S.; Veith, G. M.; Chi, M. F.; Baggetto, L.; Meng, Y. S. Probing the Electrode/Electrolyte Interface in the Lithium Excess Layered Oxide $\mathrm{Li}_{1.2} \mathrm{Ni}_{0.2} \mathrm{Mn}_{0.6} \mathrm{O}_{2}$. Phys. Chem. Chem. Phys. 2013, 15, 11128-11138.

(33) Hy, S.; Felix, F.; Rick, J.; Su, W. N.; Hwang, B. J. Direct In situ Observation of $\mathrm{Li}_{2} \mathrm{O}$ Evolution on Li-Rich High-Capacity Cathode Material, $\mathrm{Li}\left[\mathrm{Ni}_{\mathrm{x}} \mathrm{Li}_{(1-2 \mathrm{x}) / 3} \mathrm{Mn}_{(2-\mathrm{x}) / 3}\right] \mathrm{O}_{2}(0 \leq x \leq 0.5)$. J. Am. Chem. Soc. 2014, 136, 999-1007.

(34) Koga, H.; Croguennec, L.; Menetrier, M.; Mannessiez, P.; Weill, F.; Delmas, C. Different Oxygen Redox Participation for Bulk and Surface: A Possible Global Explanation for the Cycling Mechanism of $\mathrm{Li}_{1.20} \mathrm{Mn}_{0.54} \mathrm{Co}_{0.13} \mathrm{Ni}_{0.13} \mathrm{O}_{2}$. J. Power Sources 2013, 236, 250-258.

(35) Yabuuchi, N.; Yoshii, K.; Myung, S. T.; Nakai, I.; Komaba, S. Detailed Studies of a High-Capacity Electrode Material for Rechargeable Batteries, $\mathrm{Li}_{2} \mathrm{MnO}_{3}-\mathrm{LiCo}_{1 / 3} \mathrm{Ni}_{1 / 3} \mathrm{Mn}_{1 / 3} \mathrm{O}_{2}$. J. Am. Chem. Soc. 2011, 133, 4404-4419.

(36) Hy, S.; Cheng, J.-H.; Liu, J.-Y.; Pan, C.-J.; Rick, J.; Lee, J.-F.; Chen, J.-M.; Hwang, B. J. Understanding the Role of Ni in Stabilizing the Lithium-Rich High-Capacity Cathode Material Li$\left[\mathrm{Ni}_{\mathrm{x}} \mathrm{Li}_{(1-2 \mathrm{x}) / 3} \mathrm{Mn}_{(2-\mathrm{x}) / 3}\right] \mathrm{O}_{2}(0 \leqslant \mathrm{x} \leqslant 0.5)$. Chem. Mater. 2014, 26, 6919-6927.

(37) Verde, M. G.; Liu, H. D.; Carroll, K. J.; Baggetto, L.; Veith, G. M.; Meng, Y. S. Effect of Morphology and Manganese Valence on the Voltage Fade and Capacity Retention of $\mathrm{Li}\left[\mathrm{Li}_{2 / 12} \mathrm{Ni}_{3 / 12} \mathrm{Mn}_{7 / 12}\right] \mathrm{O}_{2}$. ACS Appl. Mater. Interfaces 2014, 6, 18868-18877.

(38) Kurata, H.; Colliex, C. Electron-Energy-Loss Core-Edge Structures in Manganese Oxides. Phys. Rev. B: Condens. Matter Mater. Phys. 1993, 48, 2102-2108.

(39) Riedl, T.; Gemming, T.; Wetzig, K. Extraction of EELS Whiteline Intensities of Manganese Compounds: Methods, Accuracy, and Valence Sensitivity. Ultramicroscopy 2006, 106, 284-291.

(40) Baggetto, L.; Dudney, N. J.; Veith, G. M. Surface Chemistry of Metal Oxide Coated Lithium Manganese Nickel Oxide Thin Film Cathodes Studied by XPS. Electrochim. Acta 2013, 90, 135-147.

(41) Carabineiro, S. A. C.; Bastos, S. S. T.; Orfao, J. J. M.; Pereira, M. F. R.; Delgado, J. J.; Figueiredo, J. L. Carbon Monoxide Oxidation Catalysed by Exotemplated Manganese Oxides. Catal. Lett. 2010, 134, 217-227.

(42) Shaju, K. M.; Rao, G. V. S.; Chowdari, B. V. R. X-ray Photoelectron Spectroscopy and Electrochemical Behaviour of $4 \mathrm{~V}$ Cathode, $\mathrm{Li}\left(\mathrm{Ni}_{1 / 2} \mathrm{Mn}_{1 / 2}\right) \mathrm{O}_{2}$. Electrochim. Acta 2003, 48, 1505-1514.

(43) Allen, G. C.; Harris, S. J.; Jutson, J. A.; Dyke, J. M. A Study of a Number of Mixed Transition-Metal Oxide Spinels Using X-Ray Photoelectron-Spectroscopy. Appl. Surf. Sci. 1989, 37, 111-134.

(44) Sun, Y. K.; Lee, M. J.; Yoon, C. S.; Hassoun, J.; Amine, K.; Scrosati, B. The Role of $\mathrm{AlF}_{3}$ Coatings in Improving Electrochemical Cycling of Li-enriched Nickel-Manganese Oxide Electrodes for Li-ion Batteries. Adv. Mater. 2012, 24, 1192-1196.

(45) Rosina, K. J.; Jiang, M.; Zeng, D.; Salager, E.; Best, A. S.; Grey, C. P. Structure of Aluminum Fluoride Coated $\mathrm{Li}\left[\mathrm{Li}_{1 / 9} \mathrm{Ni}_{1 / 3} \mathrm{Mn}_{5 / 9}\right] \mathrm{O}_{2}$ Cathodes for Secondary Lithium-ion Batteries. J. Mater. Chem. 2012, 22, 20602-20610. 
(46) Koga, H.; Croguennec, L.; Menetrier, M.; Mannessiez, P.; Weill, F.; Delmas, C.; Belin, S. Operando X-ray Absorption Study of the Redox Processes Involved upon Cycling of the Li-Rich Layered Oxide $\mathrm{Li}_{1.20} \mathrm{Mn}_{0.54} \mathrm{Co}_{0.13} \mathrm{Ni}_{0.13} \mathrm{O}_{2}$ in Li Ion Batteries. J. Phys. Chem. C 2014, $118,5700-5709$.

(47) Sathiya, M.; Rousse, G.; Ramesha, K.; Laisa, C. P.; Vezin, H.; Sougrati, M. T.; Doublet, M. L.; Foix, D.; Gonbeau, D.; Walker, W.; Prakash, A. S.; Ben Hassine, M.; Dupont, L.; Tarascon, J. M. Reversible Anionic Redox Chemistry in High-Capacity Layered-Oxide Electrodes. Nat. Mater. 2013, 12, 827-835.

(48) Croy, J. R.; Kim, D.; Balasubramanian, M.; Gallagher, K.; Kang, S. H.; Thackeray, M. M. Countering the Voltage Decay in High Capacity $\mathrm{xLi}_{2} \mathrm{MnO}_{3} \cdot(1-\mathrm{x}) \mathrm{LiMO}_{2}$ Electrodes $(\mathrm{M}=\mathrm{Mn}, \mathrm{Ni}, \mathrm{Co})$ for $\mathrm{Li}^{+}$Ion Batteries. J. Electrochem. Soc. 2012, 159, A781-A790. 